\title{
IMPLEMENTASI METODE HSRP PADA BANK JAWA BARAT DAN BANTEN KANTOR WILAYAH I DAN KCP SIMPANG DAGO
}

\author{
Wisnu Purwanto ${ }^{1)}$, Slamet Risnanto ${ }^{2)}$ \\ Program Studi Teknik Informatika ${ }^{12)}$ \\ Universitas Sangga Buana YPKP Bandung ${ }^{12)}$ \\ wpurwanto@bankbjb.co.id ${ }^{1)}$, Slamet.risnanto@yahoo.co.id ${ }^{2)}$
}

\begin{abstract}
ABSTRAK
Bertambahnya pegawai di lokasi KCP Simpang Dago dikarenakan relokasi Kantor Wilayah I bank Jawa Barat dan Banten (BJB) ke lokasi yang sama mengakibatkan perangkat jaringan komunikasi yang berada di KCP Simpang Dago tidak dapat mengakomodir kebutuhan dari kedua user tersebut sehingga diperlukan pemisahan jaringan namun harus dapat saling menyokong satu sama lain jika terjadi masalah. Tujuan penelitian ini untuk mengimplementasikan metode Hot Standby Router Protocol guna meningkatkan ketersediaan jaringan pada Kantor Wilayah 1 dan Kantor Cabang Pembantu Simpang Dago Bank Pembangunan Daerah Jawa Barat dan Banten (bank BJB). Metode penelitian dibagi menjadi analisa kebutuhan, Desain, pengujian dan implementasi. Sedangkan untuk metode pengumpulan data dilakukan berdasarkan observasi lokasi, wawancara, serta referensi dari studi pustaka. Penelitian ini dilakukan dengan membuat jaringan cadangan menggunakan metode HSRP pada jaringan Kantor Wilayah 1 dan Kantor Cabang Pembantu Simpang Dago Bank Pembangunan Daerah Jawa Barat dan Banten (bank BJB). pengujian dilakukan menggunakan perintah ping, dan traceroute, untuk menguji failover metode HSRP yang telah diimplementasikan. Dengan diimplementasikannya metode HSRP diharapkan ketersediaan jaringan di kedua lokasi tersebut menjadi lebih baik.
\end{abstract}

Kata Kunci : metode, observasi, traceroute, failover, ketersediaan

\section{PENDAHULUAN}

Teknologi informasi saat ini memiliki peranan yang sangat penting di segala bidang dan aspek kehidupan, baik dalam pemerintahan, pendidikan, hingga di dunia bisnis perbankan. Teknologi informasi khususnya pada jaringan komputer merupakan suatu hal yang sangat penting bagi setiap perusahaan, dimana banyak perusahaan memerlukan informasi dan data dari unit terkecil hingga ke nasabah. Penggunaan jaringan komputer yang dapat dimanfaatkan oleh perusahaan diantaranya Local Area Network (LAN) yang hanya mencakup wilayah kecil seperti gedung, kantor, atau yang lebih kecil, dan Wide Area Network (WAN) yang mencakup wilayah lebih luas dari LAN yaitu mencakup kota hingga negara yang memerlukan koneksi intranet untuk saling terhubung.
Bank BJB terdiri dari beberapa kantor wilayah, serta cabang - cabang yang berada di bawah struktural kantor wilayahnya untuk menangani permasalahannya sendiri. Saat ini, terdapat beberapa lokasi kantor yang saling berdampingan diantaranya Kantor Wilayah 1 Bank BJB dan KCP (Kantor Cabang Pembantu) Simpang Dago yang terletak di Jalan Ir. Hj. Djuanda. Seiring berjalannya waktu perangkat jaringan yang berada di KCP tidak dapat mengakomodir kebutuhan Kanwil I dan KCP itu sendiri sehingga diperlukan pemisahan jaringan namun harus dapat saling menyokong satu sama lain.

Maksud dan tujuan adalah mengoptimalisasi jaringan komputer di Kantor Wilayah I dan KCP Simpang Dago bank BJB menggunakan metode Hot Standby Router Protocol. Jika didetailkan maksud dan tujuan dibuatnya penelitian ini antara lain: 
1. Penerapan metode Hot Standby Router Protocol.

2. Merancang topologi baru yang lebih baik dari topologi sebelumnya.

Serta Manfaat yang didapatkan setelah dibuatnya penelitian ini

1. Ketersediaan jaringan komunikasi intranet Bank BJB khususnya Kantor Wilayah I dan KCP Simpang Dago menjadi lebih baik.

2. Mencegah kesalahan Komunikasi antara Kantor Wilayah I dan KCP Simpang Dago dengan Kantor Pusat.

Metode penelitian dalam pembuatan penelitian meliputi dua bagian, yaitu Analisa Penelitian dan metode Pengumpulan Data.

\section{Analisa Penelitian}

a. Analisa Kebutuhan, Pada tahap ini melakukan analisa kebutuhan pengguna, permasalah yang terjadi berkaitan dengan jaringan dari wawancara, survei lapangan pada Jaringan Kantor Wilayah I dan KCP Simpang Dago Bank BJB.

b. Desain. Setelah proses analisa kebutuhan dan data sudah didapatkan, selanjutnya adalah membuat desain topologi yang diharapkan untuk menyelesaikan permasalahan yang ada.

c. Testing, Tahap ini adalah melakukan pengujian jaringan yang telah dirancang pada tahap Desain. Hal ini dimaksudkan untuk melihat kinerja awal dari jaringan yang akan dibangun.

d. Implementasi, Dalam tahap ini menerapkan semua yang telah direncanakan pada tahap Testing secara langsung untuk menyelesaikan masalah yang ada.

\section{Metode Pengumpulan Data}

a. Observasi, Melakukan pengumpulan data dengan mengamati jaringan komunikasi pada sistem yang berjalan pada Kantor Wilayah I dan KCP Simpang Dago II bank BJB.

b. Wawancara, Melakukan wawancara langsung dengan pihak bank BJB untuk mengumpulkan data tentang permasalahan yang ada pada jaringan
Kantor Wilayah I dan KCP Simpang Dago Bank BJB.

c. Studi Pustaka, Mengumpulkan data melalui hasil dokumentasi yang diperoleh dari buku, jurnal maupun browsing dari internet. Dalam hal ini dilakukan pencarian dan pemahaman teori - teori yang berhubungan dengan penulisan laporan penelitian.

Terdapat beberapa batasan Ruang Lingkup Pekerjaan pada penulisan penelitian ini, ruang lingkup tersebut diantaranya:

1. Implementasi jaringan komputer hanya dilakukan pada jaringan intranet/jaringan lokal;

2. Implementasi metode Hot Standby Router Protocol dilakukan pada perangkat Router atau Core Layer;

3. Router yang digunakan mengacu pada standar perangkat yang telah ditetapkan oleh bank BJB;

4. Implementasi jaringan komputer tidak bergantung pada ketersediaan jaringan WAN yang disediakan oleh penyedia jasa telekomunikasi.

\section{LANDASAN TEORI}

Terdapat beberapa teori dasar terkait jaringan komputer, mulai dari terminologi, dasar-dasar teori, dan lain. Berikut ini adalah beberapa pengetahuan tentang jaringan komputer.

\section{Pengertian Jaringan Komputer}

Jaringan komputer adalah kumpulan beberapa komputer yang saling berhubungan menggunakan suatu teknologi ${ }^{[1]}$. Dua komputer dapat dihubungkan melalui kawat tembaga (copper wire), fiber optic, microwaves, infrared, dan satelit komunikasi juga dapat digunakan. Internet maupun World Wide Web (WWW) juga disebut jaringan komputer.

\section{Topologi yang digunakan}

Topologi yang digunakan adalah Topologi Tree, Jaringan topologi ini disebut juga sebagai topologi jaringan bertingkat. Topologi ini biasanya digunakan untuk interkoneksi antar sentral dengan hirarki yang berbeda. Untuk 
hirarki yang lebih rendah digambarkan pada lokasi yang rendah dan semakin ke atas mempunyai hirarki semakin tinggi. Topologi jaringan jenis ini cocok digunakan pada sistem jaringan komputer. Ciri-ciri jaringan tree/hybrid:

a. Merupakan pengembangan dari topologi jaringan star.

b. Jaringan topologi tree digunakan untuk mendukung algoritma searching dan sorting

c. Setiap tangkai (node) dalam tree akan dihubungkan dengan pusat hub yang berada pada awal trafik rangkaian.

Untuk lebih jelasnya dapat dilihat pada gambar 3 di bawah ini.

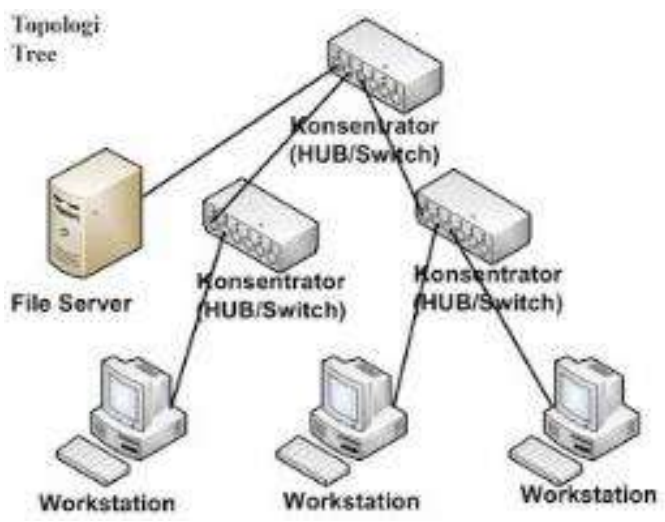

Gambar 1 : Topologi Tree

\section{Metode Failover HSRP}

HSRP adalah sebuah protocol redudancy standar cisco yang menetapkan sebuah router yang secara otomatis mengambil alih jika router yang lain gagal ${ }^{[2]}$. Salah satu cara untuk meningkatkan waktu uptime hingga mendekati 100 persen, HSRP dapat digunakan pada jaringan komputer dengan availability yang tinggi dengan menyediakan redundansi IP address network pada hop pertama routing untuk host dan jaringan komputer yang telah dikonfigurasi menggunakan sebuah IP Address default gateway.

\section{a. Dasar-dasar HSRP}

Salah satu cara untuk mencapai network uptime hingga mendekati $100 \%$ adalah menggunakan HSRP. HSRP menyediakan redundansi untuk Jaringan IP, memastikan bahwa lalu lintas data dari user dapat dipulihkan secara cepat dan transparan dari kegagalan hop pertama (Gateway) pada perangkat jaringan komputer.

Berdasarkan penjelasan operasi HSRP di atas, Berikut ini adalah beberapa istilah dalam HSRP.

Tabel 1 : Istilah dalam HSRP

\begin{tabular}{|l|l|}
\hline Term ( Istilah ) & Definition (Definisi ) \\
\hline Active Router & $\begin{array}{l}\text { Router yang meneruskan } \\
\text { paket-paket untuk virtual } \\
\text { router }\end{array}$ \\
\hline Standby Router & $\begin{array}{l}\text { Router cadangan Bila Active } \\
\text { Router Down }\end{array}$ \\
\hline Standby Group & $\begin{array}{l}\text { Kelompok router yang telah } \\
\text { dikonfigurasi HSRP untuk } \\
\text { menjadi virtual router }\end{array}$ \\
\hline
\end{tabular}

\section{b. Cara Kerja HSRP}

Gambar di bawah ini menjelaskan tentang bagaimana cara kerja dari metode HSRP.

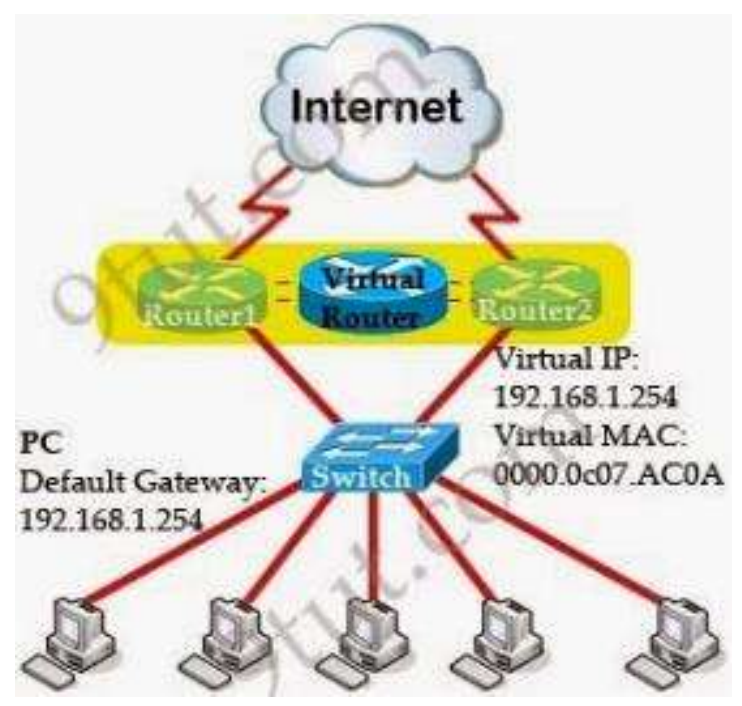

Gambar 2 : HSRP

Gambar di atas terdapat 2 router fisik, 1 router virtual, 1 switch, dan 5 client PC. Cara kerjanya adalah kedua router di atas dianggap sebagai satu router (virtual) saja, HSRP menggunakan sebuah IP dan MAC Address virtual dari dua router fisik yang berguna untuk mempresentasikan hanya satu Gateway untuk semua Host, sebagai contoh: Virtual 
IP:192.168.1.254 dan Virtual Mac Address 0000.0C07.AC0A jadi semua host akan mengarahkan gateway-nya pada IP dan Mac tersebut.

Pada protokol HSRP seluruh router yang tergabung dalam HSRP group saling bertukan informasi status dengan mengirimkan pesan Hello Packet sesama router tersebut. Setiap router meingirimkan pesan Hello Packet tersebut ke alamat spesifik. Pada protokol HSRP versi 1 pesan Hello Packet dikirimkan ke alamat IP 224.0.0.2 port UDP 1985, sedangkan untuk HSRP versi 2 pesan Hello Packet dikirimkan ke alamat IP 224.0.0.102 pada versi IOS 12.2(46)SE ke atas.

\section{ANALISA BERJALAN}

JARINGAN

\section{Tinjauan Perusahaan Bank BJB}

Bank BJB adalah bank umum milik pemerintah didaerah jawa barat dan banten yang memiliki nasabah dari berbagai lapisan berupa perorangan, pekerja, koperasi, badan usaha milik pemerintah maupun badan usaha swasta lainnya. Pihak bjb dan anak perusahaannya mempunyai 44 cabang kantor konvensional, 6 cabang kantor syariah, 135 cabang kantor pembantu konvensional, 15 cabang kantor syariah, 48 kantor untuk kas, 42 untuk payment point, 1 mobil untuk edukasi, 385 mesin atm menurut perhitungan sampai tanggal 31 desember 2010. Untuk menindak lanjuti aturan pemerintah tahun1960 nomor 33, pemerintah daerah jawa barat berdasarkan akta pendirian no. 125 tahun 1960 juncto akta nomor 152 tahun1961 dan akta nomor 84 tahun 1961 semuanya dibuat oleh notaris noezar dan seperti surat keputusan gubernur propinsi jawa barat no 7/GKDH/BPD/61 pada tanggal 20 mei 1961 membangun perusahaan daerah Pt. bank kerja pembangunan daerah jawa barat dengan modal awal berasal dari kas daerah dengan besaran dua juta lima ratus ribu rupiah.

\section{Struktur Organisasi dan Fungsi}
a. Kantor Wilyah I

Kantor Bank BJB yang membantu kantor pusat melakukan fungsi administrasi dan koordinasi terhadap beberapa kantor cabang di Wilayah Jawa Barat Bagian Tengah meliputi daerah Bandung, Cianjur, Karawang, Sukabumi, Cimahi, dan Bogor. Berikut ini adalah struktur organisasi dari Kantor Wilayah I bank BJB.

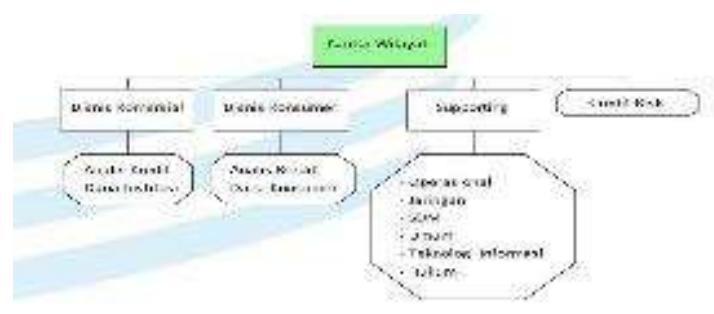

Gambar 3 Struktur Organisasi Kanwil I
b. Kantor Cabang Pembantu Simpang Dago

Kantor Cabang Pembantu Simpang Dago berada di bawah pengawasan Kantor Cabang Tamansari Bandung. KCP Simpang Dago termasuk ke dalam KCP Kategori 1 dimana dipimpin oleh seorang Pemimpin KCP dibantu oleh seorang officer Operasional dan Officer Bisnis. Berikut ini adalah gambar struktur organisasi yang ada di KCP Simpang Dago.

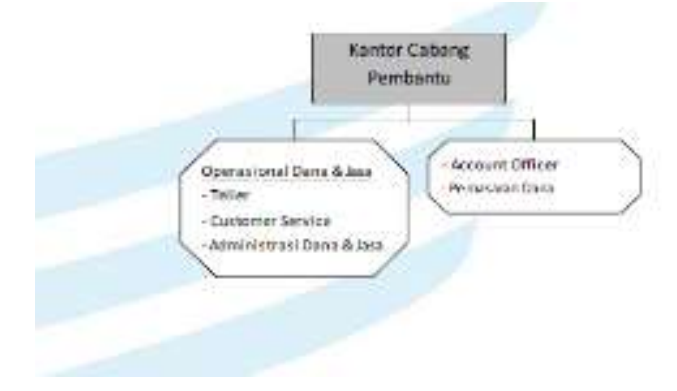

Gambar 4 : Struktur Organisasi KCP Simpang Dago

\section{Manajemen Jaringan}

Topologi Jaringan yang digunakan pada KCP Simpang Dago dan Kantor Wilayah I Bank BJB adalah Topologi Tree. Terdapat 3 Layer pada Topologi Tree tersebut, diantaranya:

a. Core Layer, Core layer adalah tulang punggung (backbone) dari jaringan komputer. Lapisan ini digunakan untuk menghubungkan jaringan komputer 
lokal ke internet atau dari jaringan LAN ke jaringan WAN.

b. Distribution Layer, Distribution Layer disebut juga layer workgroup yang menjadi penghubung antara access layer dan core layer.

c. Access Layer, Access layer disebut juga sebagai layer desktop. Fungsi utamanya adalah menjadi sarana pintu masuk bagi client untuk masuk ke dalam jaringan komputer.

Arsitektur Jaringan Komputer yang digunakan pada KCP Simpang Dago dan Kantor Wilayah I Bank BJB adalah sebagai berikut,

\section{a. LAN (Local Area Network)}

Terdapat 2 LAN (Local Area Network) yang dipisahkan berdasarkan jenis kantor menggunakan VLAN (Virtual Local Area Network) khusus untuk setiap jenis kantor. Berikut ini merupakan pembagian akses user berdasarkan VLAN, yaitu :

1) VLAN KCP Simpang Dago : VLAN
200

2) VLAN Kantor Wilayah I : VLAN 201

Media transimisi yang digunakan adalah kabel UTP dengan kategori 5c sesuai dengan standar yang ditentukan Divisi Teknologi Informasi.

\section{b. WAN (Wide Area Network)}

Jaringan WAN tersebut menggunakan jaringan komunikasi dari ISP (Internet Service Provider) Telkom dengan service IP VPN MPLS (Virtual Private Network Multi Protocol Layer Switching) dengan kecepatan 256Kbps. Media transmisi yang digunakan adalah kabel FO (Fiber Optic) yang terhubung langsung ke modem milik provider untuk diteruskan ke arah perangkat Router Bank BJB.

Seperti yang telah dijelaskan sebelumnya, Skema Jaringan Komputer yang digunakan berdasarkan pada topologi Tree. Dimana terdapat 3 layer komunikasi, Core Layer, Distribution Layer, dan Access Layer. Berikut adalah Skema Jaringan Berdasarkan Topologi yang digunakan di KCP Simpang Dago dan Kantor Wilayah I bank BJB.

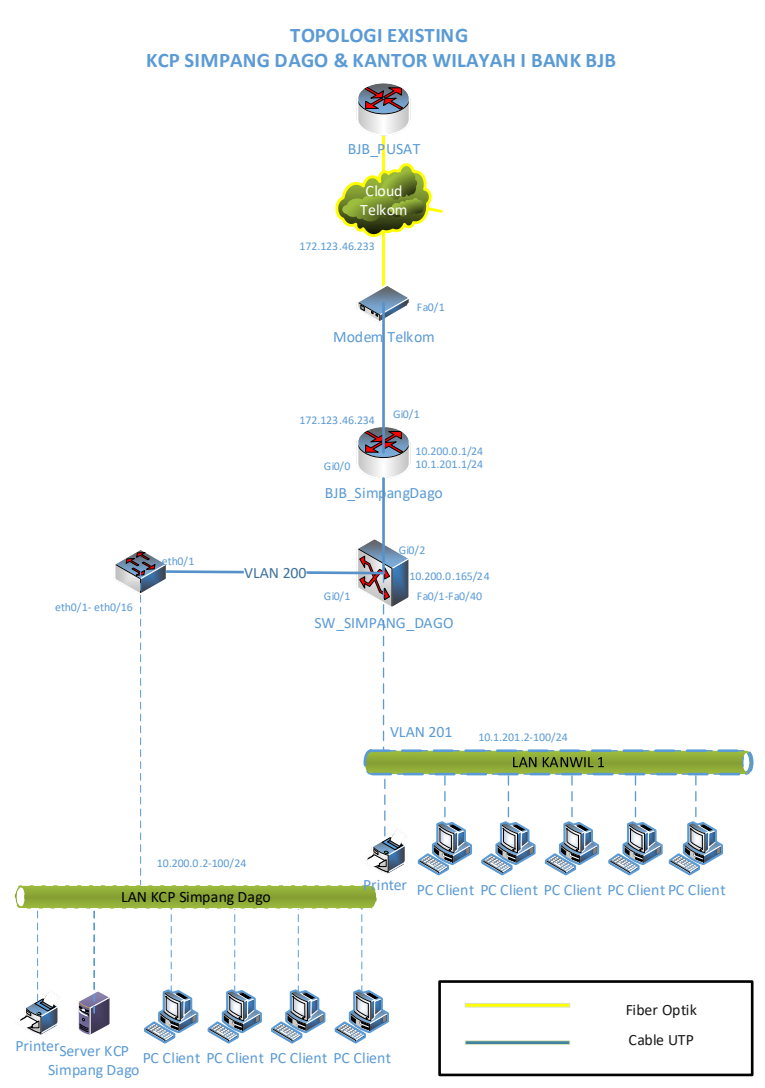

Gambar 5 : Skema Jaringan Awal

Berdasarkan standar yang digunakan oleh Bank BJB saat ini, sistem keamanan jaringan komputer yang digunakan hanya sebatas pada pembagian hak akses user berdasarkan jenis kantornya serta aplikasi yang diakses. Port yang mengarah pada Switch Akses pada Switch Distribusi dikonfigurasi berdasarkan VLAN akses usernya masing-masing, sehingga client yang terhubung ke Switch Akses tidak akan tercampur satu sama lain, baik client $\mathrm{KCP}$ Simpang Dago maupun Kantor Wilayah I.

Berikut adalah Spesifikasi Hardware dan Software Jaringan Komputer yang digunakan di KCP Simpang Dago dan Kantor Wilayah I Bank BJB berdasarkan letak layernya.

a. Core Layer, Pada Layer ini perangkat Jaringan Komputer yang digunakan adalah Router dengan Merek Cisco Tipe 1941

b. Distribution Layer, Pada Layer ini perangkat Jaringan Komputer yang digunakan adalah Switch Manageable dengan Merek Cisco Tipe Catalyst2960-TT-L 
c. Access Layer, Pada Layer ini perangkat Jaringan Komputer yang digunakan adalah Switch Unmanageable dengan Merek Allied-Telesis Tipe AT-FS724L.

Masalah yang didapat berdasarkan pengamatan yang dilakukan pada poin sebelumnya yaitu :

a. Pada core layer hanya terdapat 1 router yang menangani routing paket data yang berasal dari KCP Simpang Dago maupung Kantor Wilayah I menuju ke Kantor Pusat. Jika terjadi masalah atau Router tersebut rusak maka client yang ada di KCP Simpang Dago maupun Kantor Wilayah tidak dapat berkomunikasi dengan Kantor Pusat yang mengakibatkan kegiatan operasional perbankan terganggu.

b. Belum terdapat perangkat Switch Akses pada VLAN Kantor Wilayah I. Saat ini Switch Distribusi berfungsi ganda, sebagai Layer Distribusi juga Layer Akses bagi VLAN Kantor Wilayah I. Ini dikhawatirkan dapat mengganggu performa dari Switch Distribusi tersebut.

c. Kantor wilayah I dan KCP Simpang Dago BJB membutuhkan 1 link WAN baru yang berbeda provider dengan kecepatan yang sama, untuk mengakomodir apabila link existing Provider Telkom yang saat ini digunakan Down. Di samping itu, link backup tersebut berfungsi untuk membagi beban Jaringan Komunikasi dari dan menuju Kantor Pusat.

d. Pihak Bank BJB menginginkan pemisahan topologi jaringan antara KCP Simpang Dago dan Kantor Wilayah I, melalui penambahan perangkat jaringan komputer seefektif mungkin namun tetap sesuai dengan ketentuan standar perangkat yang telah ditetapkan oleh Divisi Teknologi Informasi.

Setelah mengidentifikasi masalah yang ada di Kantor wilayah 1 dan KCP Simpang Dago Bank BJB, solusi yang diajukan penulis adalah melakukan penambahan dan konfigurasi satu router pada Core Layer, penambahan satu Switch Akses untuk VLAN Kantor Wilayah I, dan satu link WAN dari penyedia jasa komunikasi baru yang terhubung ke Kantor Pusat.
Jika dituliskan dalam tabel penambahan yang akan diimplementasikan menjadi seperti berikut.

Tabel 2 : List Penambahan Perangkat \& Jaringan

\begin{tabular}{|c|c|c|c|c|}
\hline No & Layer & $\begin{array}{l}\text { Jenis } \\
\text { Penambahan }\end{array}$ & $\begin{array}{l}\text { Merek/ } \\
\text { Provider }\end{array}$ & Ket. \\
\hline 1 & $\begin{array}{l}\text { Core } \\
\text { Layer }\end{array}$ & $\begin{array}{l}\text { Perangkat } \\
\text { Router }\end{array}$ & Cisco & $\begin{array}{l}\text { Tipe } \\
1941\end{array}$ \\
\hline 2 & $\begin{array}{l}\text { Core } \\
\text { Layer }\end{array}$ & Link & $\begin{array}{l}\text { JATEL } \\
\text { (JABAR } \\
\text { TELEM } \\
\text { ATIKA) }\end{array}$ & $\begin{array}{l}\text { Speed } \\
\text { 256Kbps }\end{array}$ \\
\hline 3 & $\begin{array}{l}\text { Access } \\
\text { Layer }\end{array}$ & $\begin{array}{l}\text { Perangkat } \\
\text { Switch } \\
\text { Unmanage }\end{array}$ & $\begin{array}{l}\text { Allied- } \\
\text { Telesis }\end{array}$ & $\begin{array}{l}\text { Tipe AT- } \\
\text { FS724L }\end{array}$ \\
\hline
\end{tabular}

\section{RANCANGAN SISTEM JARINGAN USULAN}

\section{Manajemen Jaringan Usulan}

Topologi Jaringan yang disulkan tetap menggunakan topologi Tree seperti yang saat ini telah diimplementasikan pada KCP Simpang Dago dan Kantor Wilayah I Bank BJB. layer yang digunakan tetap 3 Layer, namun terdapat penambahan perangkat pada Core Layer dan Access Layer untuk menghindari Single Point of Failure pada layer tersebut.

Jumlah LAN tetap menggunakan 2 LAN (Local Area Network) seperti kondisi existing dan dipisahkan berdasarkan jenis kantor menggunakan VLAN (Virtual Local Area Network). Penomoran VLAN pun tetap berdasarkan standar penomoran VLAN yang telah ditetapkan Bank BJB, yaitu berdasarkan kode Kantor dimana :

a. Kode Kantor KCP Simpang Dago : 0200, maka VLAN ID KCP Simpang Dago : VLAN 200

b. Kode Kantor Wilayah I : 0201, maka VLAN ID Kantor Wilayah I : VLAN 201

Berikut ini adalah gambar skema jaringan usulan beserta IP Address dan segmen network untuk KCP Simpang Dago dan Kantor 
Wilayah I Bank BJB berdasarkan alternatif pemecahan masalah yang telah dijelaskan pada BAB III.

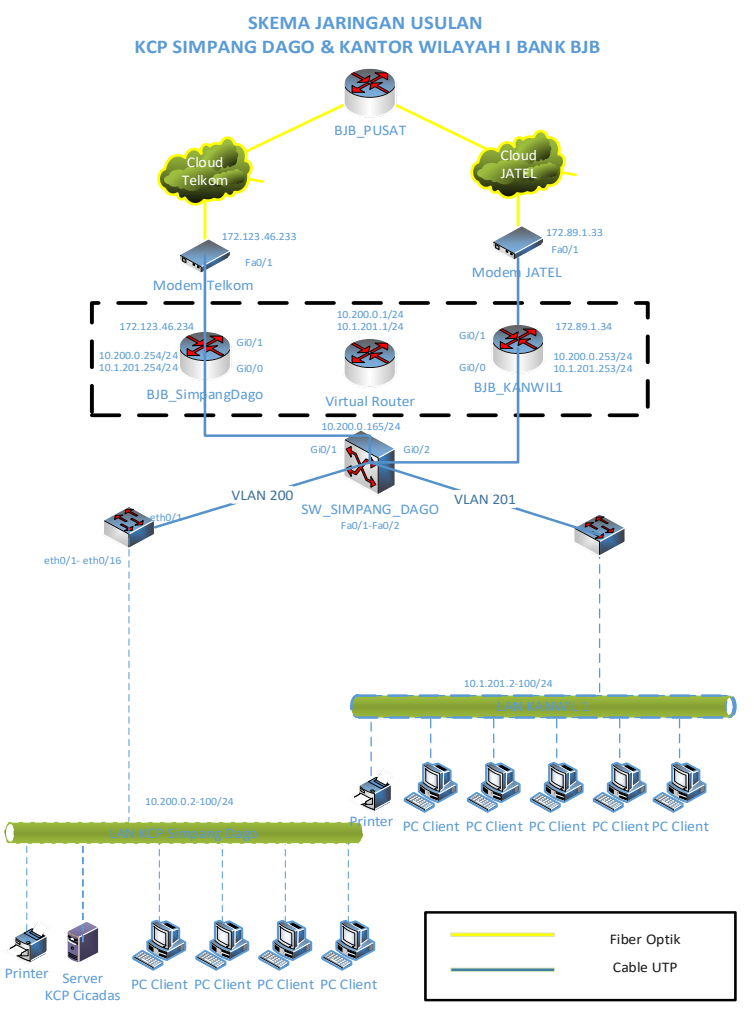

Gambar 6 : Skema Jaringan Usulan

2. Konfigurasi HSRP

a. Core Layer

Pertama adalah memberikan real IP Address per VLAN untuk perangkat router KCP Simpang Dago dan Kantor Wilayah I bank BJB. Port yang ada pada Cisco 1941 adalah port layer 3, sehingga jika ingin mengkonfigurasi VLAN dan IP Address di dalamnya harus menggunakan enkapsulasi dengan protokol $\operatorname{dot} 1 Q$. Berikut adalah cara mengkonfigurasi port di setiap router.

\section{1) Router KCP Simpang Dago}

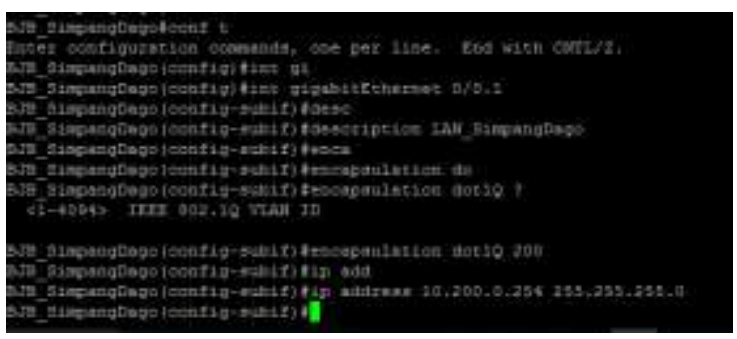

Gambar 7 : konfigurasi subinterface port KCP Simpang Dago

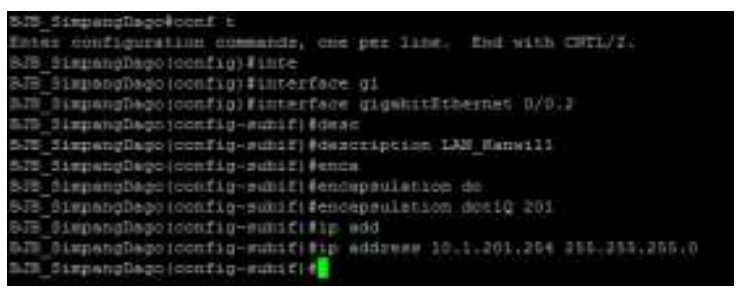

Gambar 8 : Konfigurasi subinterface port Kanwil I

2) Router Kantor Wilayah I

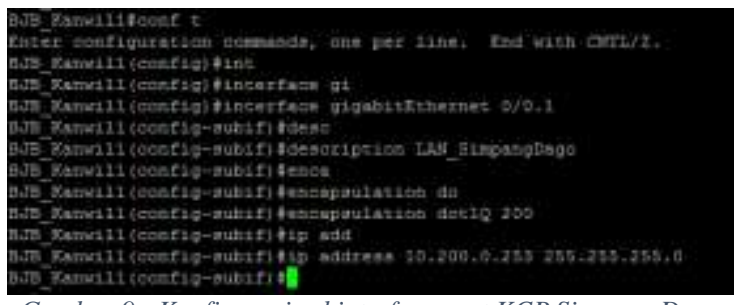

Gambar 9 : Konfigurasi subinterface port KCP Simpang Dago

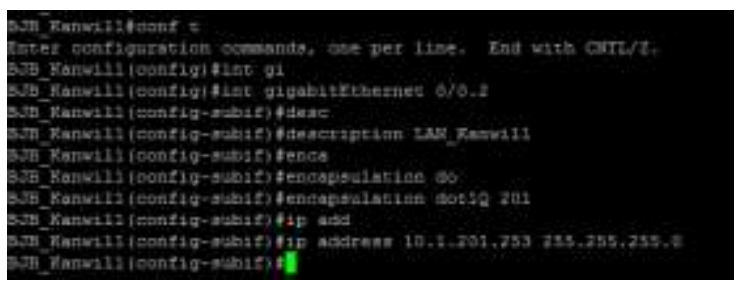

Gambar 10 : Konfigurasi subinterface port Kanwil I

Setelah mengkonfigurasi IP Address real di setiap router untuk setiap VLAN, selanjutnya adalah melakukan konfigurasi HSRP sebagai metode fail-over yang akan digunakan.

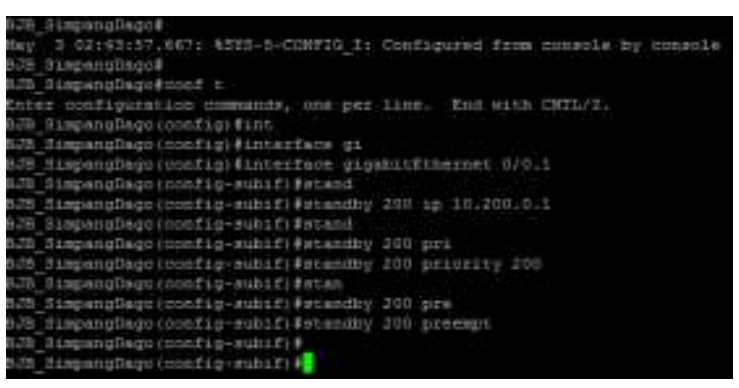

Gambar 11 : Konfigurasi HSRP VLAN 200 di Router KCP Simpang Dago

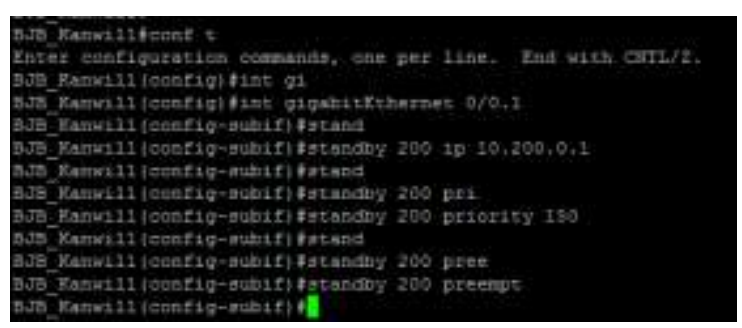

Gambar 12 : Konfigurasi HSRP VLAN 200 di Router Kantor Wilayah I 


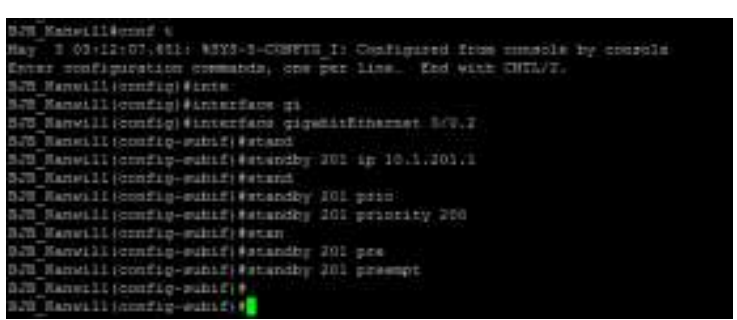

Gambar 13 : Konfigurasi HSRP VLAN 201 di Router Kantor Wilayah I

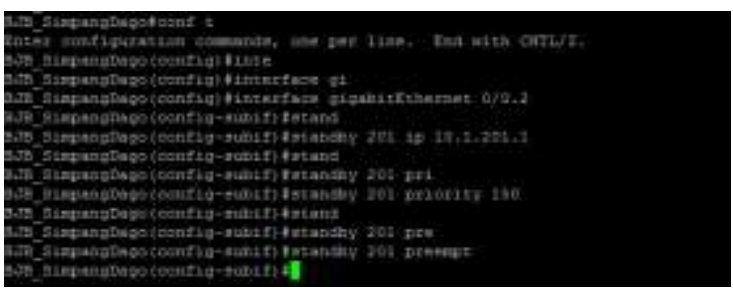

Gambar 14 : Konfigurasi HSRP VLAN 201 di Router KCP Simpang Dago

b. Distribution Layer

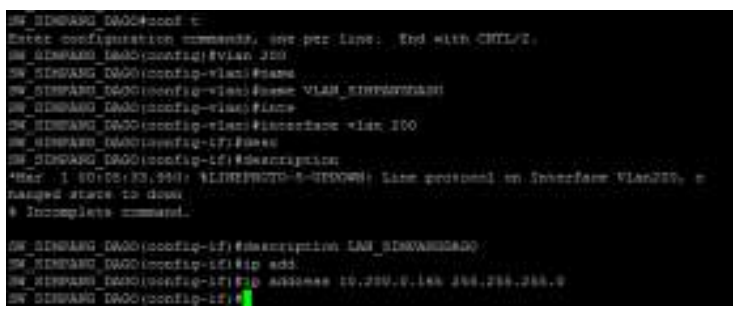

Gambar 15 : Konfigurasi VLAN dan IP Address VLAN 200 KCP Simpang Dago

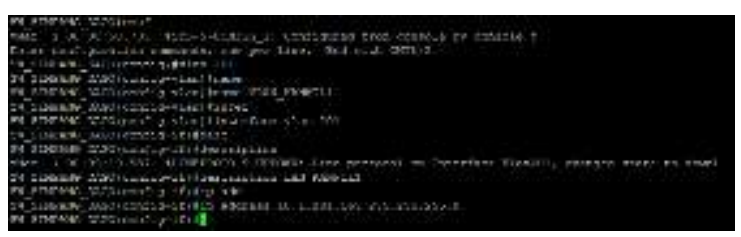

Gambar 16 : Konfigurasi VLAN dan IP Address VLAN 201 Kantor Wilayah 1

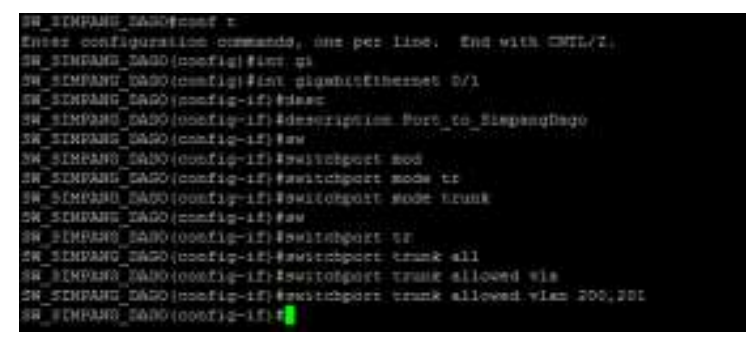

Gambar 17 : Konfigurasi Port trunk interface GigabitEthernet0/1

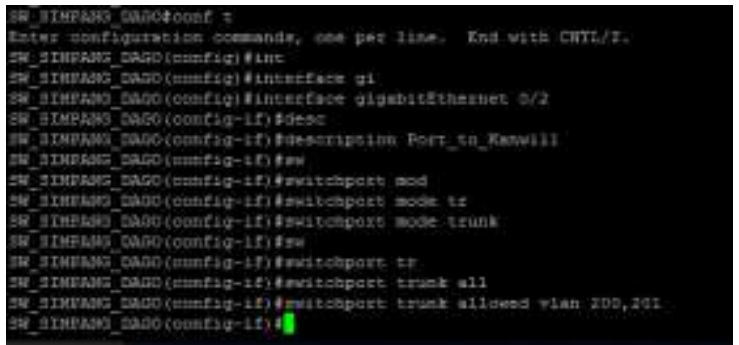

Gambar 18 : Setting port trunking interface GiO/2

3. Pengujian Jaringan

a. Test Fail Router Jaringan Awal

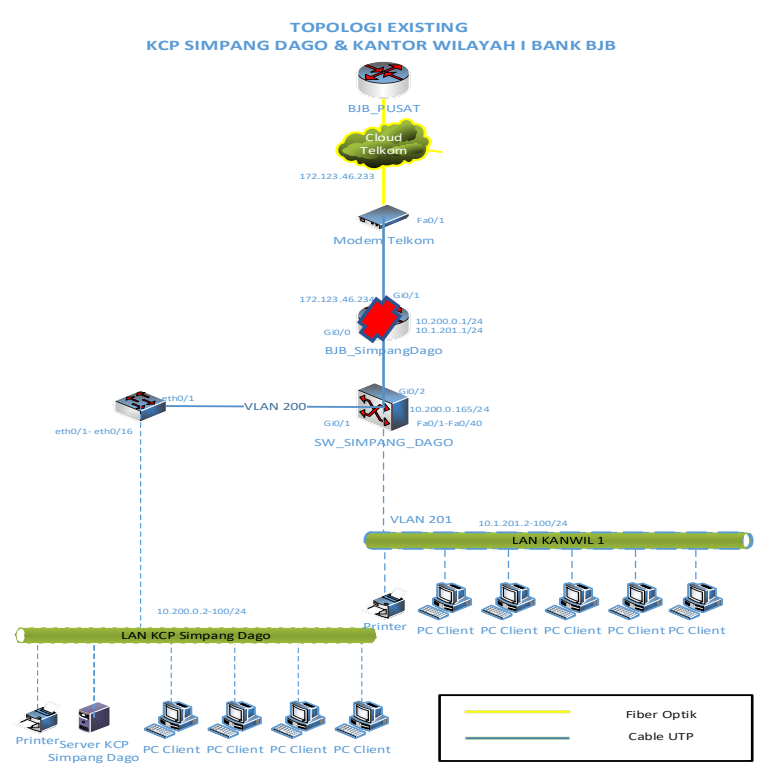

\section{Gambar 19 : Skema/Topologi Test Router Fail} Jaringan Awal

Dapat dilihat bahwa test dilakukan dengan mematikan router ke arah kantor pusat, selanjutnya test dilakukan dengan ping dan tracerouter. Berikut ini adalah capture dari uji ping dan traceroute ke arah kantor pusat.

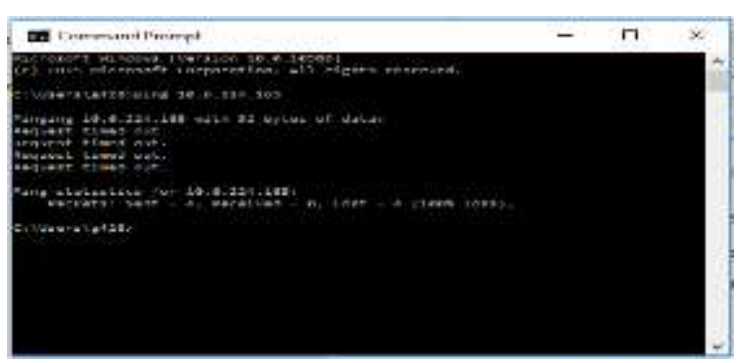

Gambar 20 : Test Ping saat uji Router Fail

Dapat dilihat bahwa uji ping tidak berhasil, ditunjukkan dengan server tidak merespon request ping dari client. 


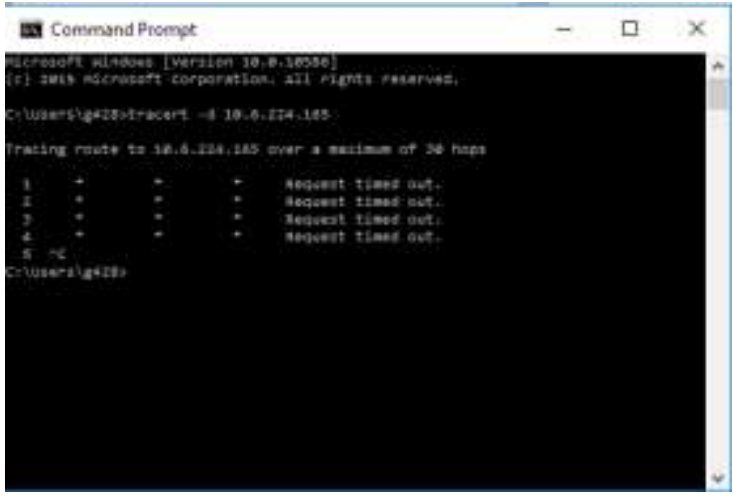

Gambar 21 : Uji Traceroute saat Test Router Fail

Dapat dilihat pula bahwa uji traceroute pun tidak berhasil, tidak ada hop/jalur yang dilewati menuju kantor pusat.

Berikut ini adalah grafik MRTG dari penggunaan bandwidth sebelum implementasi HSRP di KCP Simpang Dago dan Kantor Wilayah I Bank BJB.

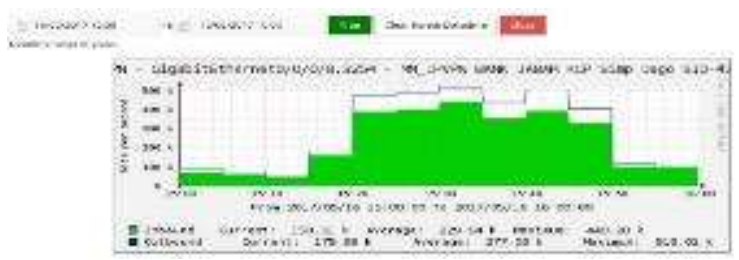

Gambar 22 : Hasil Capture Penggunaan Bandwidth Jaringan Awal

b. Test Fail Router Jaringan Akhir

Berikut adalah beberapa skenario dalam pengujian jaringan akhir

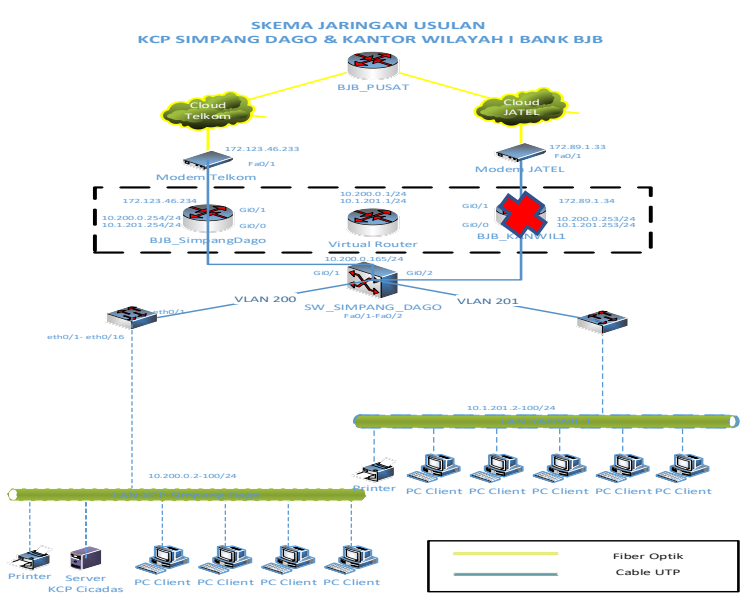

Gambar 23 : Test Fail Router KCP Simpang Dago
Berikut ini adalah capture dari uji ping dan traceroute ke arah kantor pusat pada saat Router KCP Simpang Dago Fail.

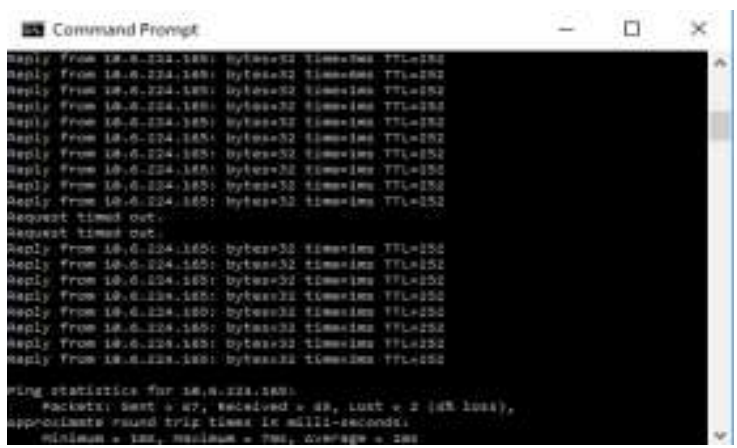

Gambar 24 : Uji Ping Router KCP Simpang Dago Fail

Untuk lebih jelasnya perpindahan jalur tersebut dapat dilihat pada test Traceroute di bawah.

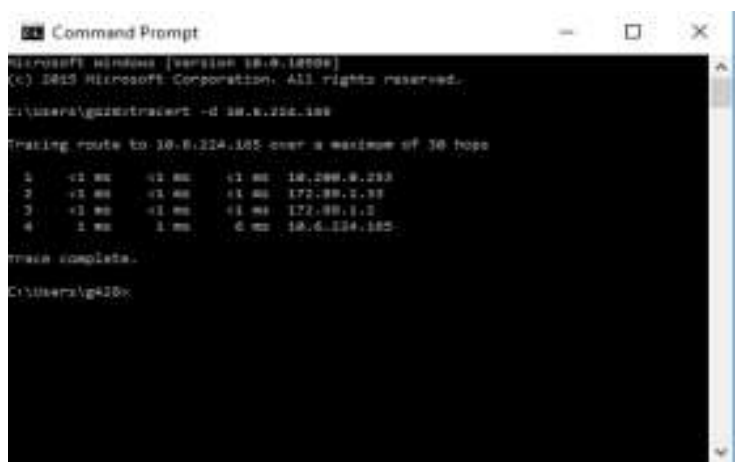

Gambar 25 : Uji Traceroute saat Router KCP Simpang Dago Fail

Gambar di atas menunjukkan bahwa hop/jalur yang dilewati oleh user KCP Simpang Dago telah berpindah.

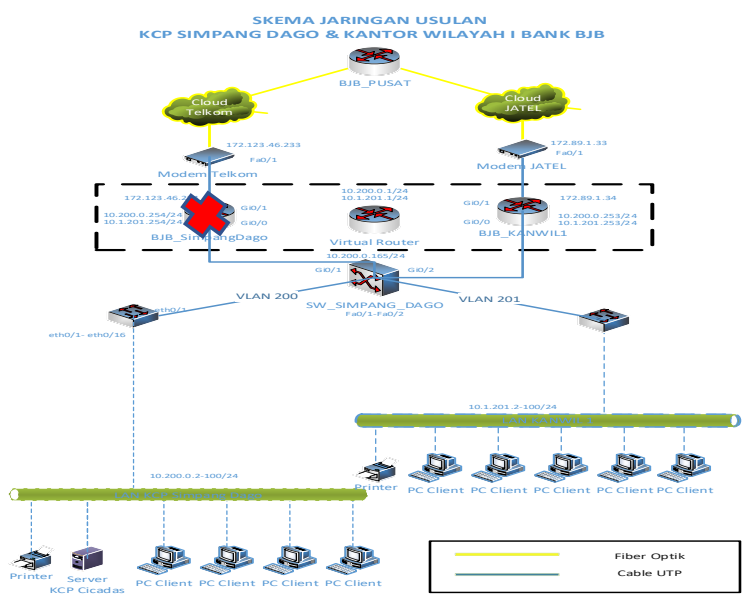

Gambar 26 : Test Fail Router Kantor Wilayah I 
Berikut ini adalah capture dari uji ping dan traceroute ke arah kantor pusat pada saat Router Kantor Wilayah I Fail.

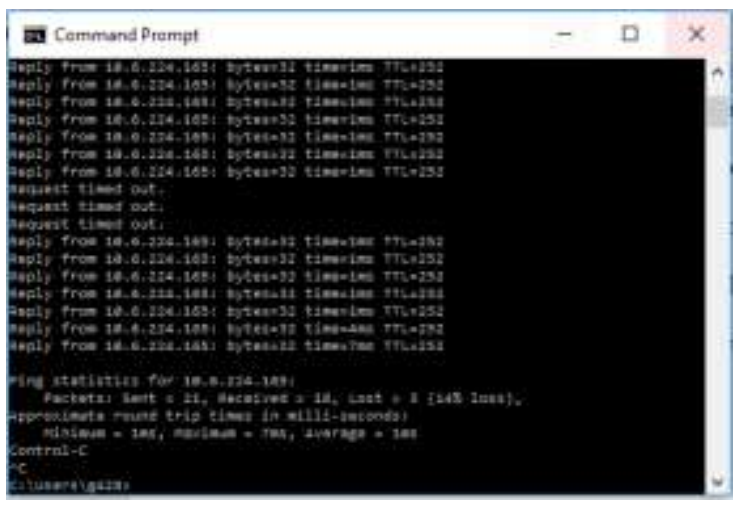

Gambar 27 : Uji Ping Router Kantor Wilayah I Fail

Berikut ini uji perpindahan menggunakan test Traceroute.

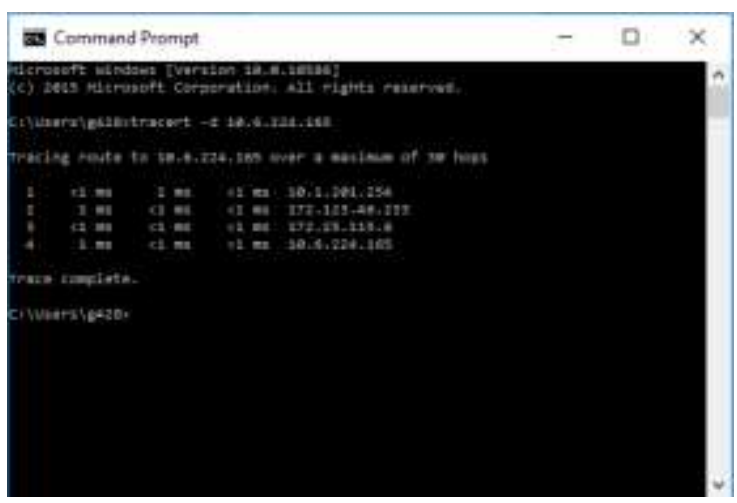

Gambar 28 : Uji Traceroute saat Router Kantor Wilayah I Fail

Gambar di atas menunjukkan bahwa hop/jalur yang dilewati oleh user Kantor Wilayah I telah berpindah

Setelah dilakukan implementasi metode HSRP di lokasi KCP Simpang Dago dan Kantor Wilayah I Bank BJB, beban traffic dapat terbagi ke dua router dan dua provider. Berikut ini adalah hasil grafik MRTG dari penggunaan bandwidth di KCP Simpang Dago dan Kantor Wilayah I Bank BJB.

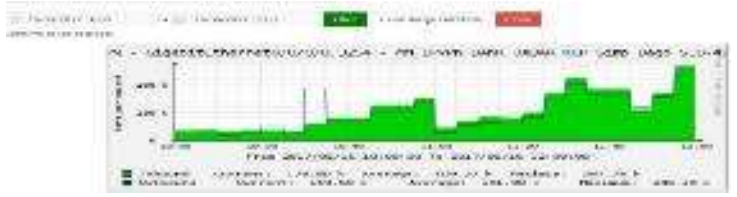

Gambar 29 : Grafik penggunaan Bandwidth KCP Simpang Dago

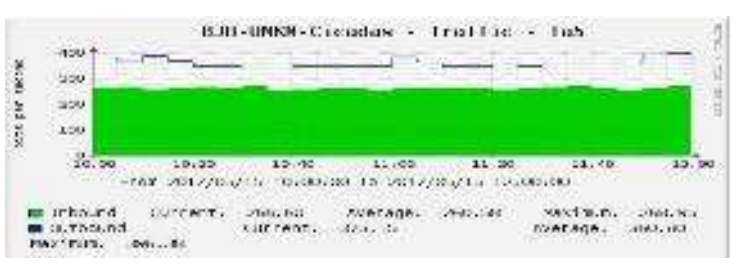

Gambar 30 : Grafik penggunaan Bandwidth Kantor Wilayah I

\section{PENUTUP}

Setelah dilakukan implementasi metode HSRP pada KCP Simpang Dago dan Kantor Wilayah I bank bjb, serta berdasarkan pada identifikasi masakah yang telah dijelaskan pada bahasan sebelumnya, maka dapat disimpulkan sebagai berikut:

1. Pada topologi baru KCP Simpang Dago \& KANWIL I Bank BJB menggunakan tambahan router pada core layer membuktikan bahwa kantor tersebut masih dapat terhubung jika salah satu Router tersebut down.

2. Pada Akses layer ditambahkan 1 perangkat switch, sehingga kinerja switch distribusi dapat lebih optimal, karena akses dari client Kantor Wilayah I telah ditangani oleh switch akses Kantor Wilayah I.

3. Pemisahan jaringan telah berhasil dilakukan berdasarkan pembagian beban sesuai asal client melalui penambahan 1 link provider tambahan untuk mengakomodir kebutuhan jaringan komputer dari client Kantor Wilayah I Bank BJB, yang sebelumnya bertumpu pada jaringan KCP Simpang Dago.

4. Peningkatan availability pada setiap layer

\section{DAFTAR PUSTAKA}

[1]. Tanenbaum, S, Andrews. Wetherall, J, David. 2011. Computer Network Prentice Hall.

[2]. sebatekno, 2016, Terminologi FHRP, HSRP, VRRP dan GLBP. Diambil dari:

http://www.sebatekno.com/terminolo gi-fhrp-hsrp-vrpp-dan-glbp.

[3]. Goldman, J.E. dan Rawles, P.T. Fourth Edition. 2004. Applied Data Communications: A 
Business-Oriented Approach. New York: Wiley.

[4]. Sofana, I. 2012. CISCO CCNA dan Jaringan Komputer. Bandung : Informatika Bandung.

[5]. Sofana, I. 2012. CISCO CCNP dan Jaringan Komputer. Bandung: Informatika Bandung.

[6]. Sofana, I. 2013. Membangun Jaringan Komputer. Mudah membuat jaringan komputer (Wire \& Wireless) untuk Pengguna Windows dan Linux. Bandung: Informatika Bandung.

[7]. Taufik, M. 2015. The Way To Be Cisco Warior, Teory \& Practice. Jakarta: ID-Networkers

[8]. Sukaridhoto, S. 2014. Buku Jaringan Komputer I. Surabaya: Politeknik Elektronika Negeri Surabaya.

[9]. 3com. 2001. Understanding IP Addressing: Everything You Ever Wanted To Know. Santa Clara: 3 com Corporation.

[10]. Cisco. 2011. IP Addressing Guide. San Jose: Cisco System, Inc.

[11]. Cisco. 2006. Cisco IOS IP Configuration Guide Release 12.2. San Jose: Cisco System, Inc.

[12]. Cisco. 2006. Hot Standby Router Protocol Features and Functionality. Diambil dari: http://www.cisco.com/c/en/us/sup port/docs/ip/hot-standby-routerprotocol-hsrp/9234hsrpguidetoc.html. (13 April 2017)

[13]. Cisco. 2014. Cisco 1941 Series Integrated Services Routers Data sheet. Diambil dari: http://www.cisco.com/c/en/us/pro ducts/collateral/routers/1900series-integrated-services-routersisr/data_sheet_c78_556319.html. (14 April 2017)

[14]. Cisco. 2014. Cisco Catalyst 2960$S$ and 2960 Series Switches with LAN Base Software Data Sheet. Diambil http://www.cisco.com/c/en/us/pro ducts/collateral/switches/catalyst2960-series-

switches/product_data_sheet0900a ecd80322c0c.html. (14 April 2017)

[15]. Allied-Telesis. 2017. FS724L. Diambil dari: http://www.alliedtelesis.com/prod ucts/switches/fs7241. (14 April 2017)

[16]. Bank BJB. 2017. Sekilas Bank BJB. Diambil dari: http://www.bankbjb.co.id/id/corpo rate-website/hubunganinvestor/tentang-bank-bjb/sekilasbank-bjb.html. (14 April 2017)

[17]. Bank BJB. 2017. Struktur Organisasi. Diambil dari: http://www.bankbjb.co.id/id/corpo rate-website/hubunganinvestor/tentang-bankbjb/struktur-organisasi.html. April 2017)

[18]. Blog. 2013. What is OSI Model \& the Overall Explanation of ISO 7 Layers. Diambil dari: http://nhprice.com/what-is-iosmodel-the-overall-explanation-ofios-7-layers.html. (14 April 2017)

[19]. Reeshil, N. 2011. Network Architectures : Layers of OSI model and TCP/IP model. Diambil dari:

https://hubpages.com/technology/ OSI-model-and-TCPIP-model. (15 April 2017) 